\title{
Eliciting Smallholder Farmers' Tradeoffs and Preferences on the Attributes of Climate Smart Agriculture in the Breadbasket Areas of Tanzania Using a Conjoint Experiment Method
}

\author{
Kassim R. Mussa ${ }^{1, ~ *, ~ J o s e p h a t ~ A . ~ S a r i a ~}{ }^{2}$, Lughano J. M. Kusiluka ${ }^{4}$, Noorali T. Jiwaji ${ }^{2}$, \\ Brown Gwambene ${ }^{3}$, Noah M. Pauline ${ }^{3}$, Nangware K. Msofe ${ }^{2}$, Juma A. Tegeje ${ }^{1}$, Innocent Messo ${ }^{2}$, \\ Sixbert S. Mwanga ${ }^{3}$ \\ ${ }^{1}$ Department of Physical Sciences, Sokoine University of Agriculture, Morogoro-Tanzania \\ ${ }^{2}$ Department of Environmental Studies, Open University of Tanzania, Dar es Salaam-Tanzania \\ ${ }^{3}$ Institute of Resource Assessment, University of Dares Salaam, Dar es Salaam-Tanzania \\ ${ }^{4}$ Faculty of Veterinary Medicine, Sokoine University of Agriculture, Morogoro-Tanzania
}

Email address:

kassimr@gmail.com (K. R. Mussa)

To cite this article:

Kassim R. Mussa, Josephat A. Saria, Lughano J. M. Kusiluka, Noorali T. Jiwaji, Brown Gwambene, Noah M. Pauline, Nangware K. Msofe, Juma A. Tegeje, Innocent Messo, Sixbert S. Mwanga. Eliciting Smallholder Farmers' Tradeoffs and Preferences on the Attributes of Climate Smart Agriculture in the Breadbasket Areas of Tanzania Using a Conjoint Experiment Method. International Journal of Environmental Protection and Policy. Vol. 3, No. 6, 2015, pp. 188-193. doi: 10.11648/j.ijepp.20150306.12

\begin{abstract}
While policy and decision-makers are striving to enhance food security amidst maddening impacts of climate change, climate smart agriculture is thought of as a promising breakthrough for responding to climate change impacts in Tanzania and elsewhere in the world as it strives to increase food productivity; build resilience of agricultural systems to climate change impacts and reduce agricultural greenhouse gas emission. Studies show that agricultural sector is both, a cause and a victim of climate change. It significantly contributes greenhouse gases to the atmosphere. However, achieving climate change mitigation through agriculture without compromising food security is a huge policy and research challenge, some scientists say, it is practically impossible. This study sought to determine tradeoffs and preferences of smallholder farmers on the attributes climate smart agricultural practices, specifically modeling choices of smallholder farmers using choice experiment method. Upon estimating three different models, positive utilities were observed in high productivity, Moderate and low GHG emission as well as on moderate and high resilient farming systems. Smallholder farmers showed a complete disutility on low and moderate agricultural productivity, high GHG emission and low resilient farming systems. The models therefore justified the fact that, attaining more yield without a compromise in greenhouse gas emission reduction targets is a blue-sky dream. In order to concisely inform policy, more research on farmers' preference and tradeoff on the attributes is needed to establish a scientific and logical progression about the tradeoffs people are willing to make with regard to the attributes of climate smart agriculture practices.
\end{abstract}

Keywords: Smallholder Farmers, Preference Modeling, Climate Smart Agriculture, Choice Experiment

\section{Introduction}

Smallholder farmers in the breadbasket areas of Tanzania are under threat from climate change impacts as they inhabit areas that are highly dependent on farming systems which are sensitive to the already volatile climate. Therefore, policy and decision-makers are striving to intensify agriculture in order to enhance food security amidst maddening impacts of climate change. However, in addition to the policymakers' effort to enhance food security under the changing climate, climate smart agriculture (CSA) is also thought of as a promising breakthrough for responding to climate change impacts in Tanzania. CSA strives to attain three main goals, which are increasing food productivity; building resilience of agricultural systems to climate change impacts and reducing agricultural greenhouse gas emission through promoting efficient use of 
land, water, soil and other environmental resources. Arguably, agriculture directly accounts for about $14 \%$ of global greenhouse gas emissions or $25 \%$ [4], if agriculture-driven deforestation is included. This makes agriculture as big a contributor to climate change as the energy sector [7]. Although agriculture is the sector most vulnerable to climate change, it is a significant contributor of greenhouse gases emissions.

In that regard therefore, the Alliance for Green Revolution in Africa (AGRA) through its Environment Policy Action Node in Tanzania, has proposed a number of CSA practices for the breadbasket areas of the Southern Highlands of Tanzania through the project titled "Securing smallholder farm production Against Climate Induced Risks". However, attaining higher yields, more carbon in the soil and crops and greater resilience to prolonged dry spells and unpredictable rainfall seasons are not supposed to be alternative targets but parallel outputs of climate-smart agriculture. In reality though, a trade-off in the three objectives of climate smart agriculture is inevitable, and thus achieving mitigation in agriculture without compromising food security is a huge policy and research challenge.

Generally, there is a daunting scarcity of empirical data on the economic appreciation of local preferences and choices on mitigation and adaptation measures all over the world. The trade-offs people make are always underestimated and probably are ignored. This has been leading to unsuccessful climate change interventions in Tanzania and elsewhere in the world. It is clear that the future of agricultural productivity in Tanzania is intertwined with climate change impacts, and hence immediate adaptation measures are necessary [8]. Accordingly, rains are increasingly declining in most parts of the country and cycles are detrimentally changing $[21,15,12]$. Such changes in climatic variables are expected to alter the characteristics of the agro-ecological zones, leading to reduced yields of some crops such as maize by $33 \%$ nationally [18]. This projection in crop yield reduction is in line with the prediction of many researchers for the same crop, which showed that maize will decrease by between $16 \%-35 \%$ by 2050 [4]. It estimated that by the 2080 s, the world agricultural productivity could decline by $3-16 \%$, with the loss in Africa projected to be $17-28 \%$ [6].

It has further been reported that smallholder farmers are always vulnerable to climate change because they face various socio-economic, demographic, and policy trends that limit their capacity to cope with climate change $[14,10]$. Probably, the ignored preferences and perceptions are some of the socio-economic and policy trends exacerbating vulnerability of smallholder farmers and other marginalized communities to the impacts of climate change.

It is thus argued that improved integration of economic and social science expertise in climate change studies is highly needed [20, 13, 16]. Nevertheless, while policy, decision-makers, researchers and practitioners are striving to make climate smart agriculture a workable solution to climate change impacts on smallholder farmers in the breadbasket areas of Tanzania, the success of this effort hinges on the willingness of the farmers themselves to adopt the practices, which is mainly influenced by the attributes of the climate smart practices themselves. Even though science is very clear about the vulnerability of smallholder farmers to climate change impacts, farmers themselves do not perceive the climate risk with the same weight as science provides. Therefore, farmers who do not feel vulnerable to climate change impacts are likely to go for the status quo (do nothing) scenario of crop productivity and climate change impacts.

It is thus imperative to assess farmers' preferences to climate change management strategies. In that regard, the basic research questions which guided this study are; (a) How much are smallholder farmers ready to trade-off among the three goals of climate smart agriculture (i.e. increased productivity, reduced agricultural greenhouse gas emissions and increased agricultural resilience (b) What aspects of climate smart agricultural practices are the most desirable to smallholder farmers? (c) Do farmers' trade-offs and choices enhance or further constrain the ability of smallholder farmers to adapt to climate change?

This study therefore sought to determine the tradeoffs and preferences of smallholder farmers on the proposed climate smart agricultural practices, specifically seeking to model the choices of smallholder farmers on the attributes of climate smart agricultural practices under different climate change and policy scenarios. The study will contribute to the scanty (if any) literature on choice modeling in climate change adaptation and mitigation in Tanzania. This study provides important additional information for cost-benefit analysis of climate smart agriculture and therefore feed into climate change adaptation and mitigation policies in Tanzania. An integration of economic and climate change adaptation is another academic contribution of this study, as it has been proven that very few climate change adaptation and mitigation studies from an economic point of view have been conducted.

\section{Methods and Approaches}

\subsection{Study Area Description}

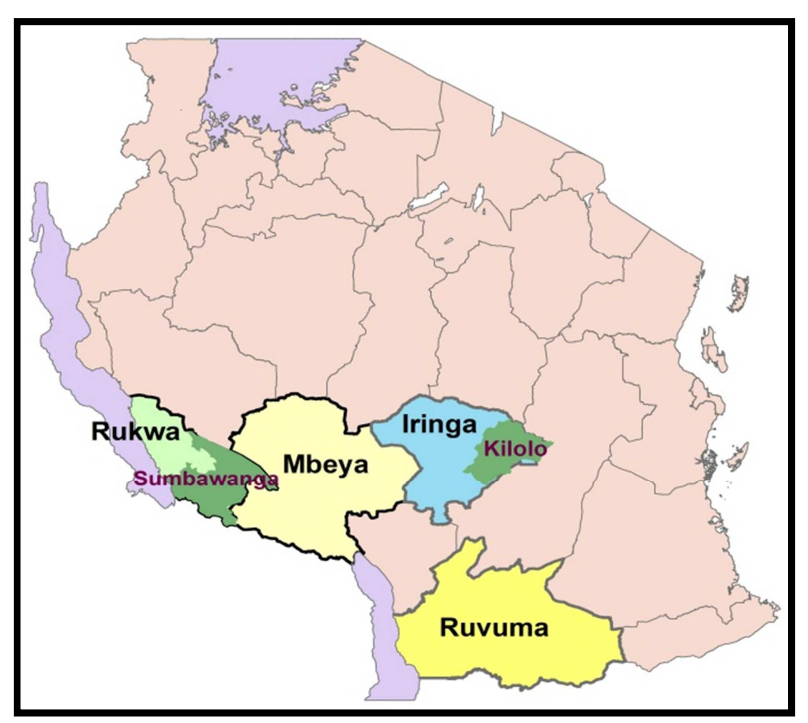

Figure 1. Map of the study area. 
This study was carried out in the breadbasket regions of Tanzania, which fall under two Agro-ecological zones, (Northern highlands which lie between 1000-2500m above sea level), characterized by reliable bimodal rainfall, ranging from $1000-2000 \mathrm{~mm}$ per year and the Southern and Western highlands, characterized by undulating plains to dissected hills rising between 1200 to $2300 \mathrm{~m}$ above sea level. Rainfall pattern is mainly unimodal ranging from $1000-2000 \mathrm{~mm}$ per year [1].

\subsection{Modeling Preferences of Smallholder Farmers: A Theoretical and Empirical Overview}

With choice experiment, a three-step design was adopted. The steps are; (i) choice model specification, (ii) development of a choice experiment survey and (iii) administering of choice experiment. The attributes and attribute levels of the choice model were identified through a series of focus group discussions, key informant interviews, literature reviews and pilot surveys. The CE data were collected using a face-to-face interview approach. SPSS Software was used for data handling and analysis. CSA factors and their values were defined by the researchers well in advance, being informed by the existing body of literature on climate smart agriculture, smallholder farmers' vulnerability and preferences with regard to adapting to potential and the current climate change impacts. The various combinations of the attribute/factor values yielded fictive combinations of the CSA strategy that were ranked by the smallholder farmers in the Southern highlands breadbasket areas of Tanzania (Table 1).

A full factorial experimental design which combined every level of each CSA attribute/factor with every level of all other attributes was used. This experiment was constructed with three attributes $(n=3$, Productivity, GHG Emission and Agricultural resilience to climate change impacts) each of which had three levels $(\mathrm{L}=3)$ as shown in Table 1 . Therefore, the number of profiles (np) generated for a full factorial design was $L^{n}=9$ profiles. Using Conjoint Analysis technique, metric partial utilities from the ranking results were derived, the summation of which resulted in metric total utilities.

Table 1. A Conjoint Plan.

\begin{tabular}{llll}
\hline Card ID & Agricultural Productivity (APD) & $\begin{array}{l}\text { Agricultural Greenhouse Gas } \\
\text { Emission (AGHGE) }\end{array}$ & $\begin{array}{l}\text { Agriculture Climate Change } \\
\text { Resilience (ACCR) }\end{array}$ \\
\hline 1 & Low Productivity & Low GHG emission & Low resilient farming \\
2 & High productivity & Hoderate GHG Emission & High resilient farming \\
3 & Low Productivity & Low GHG emission & Moderate resilient farming \\
4 & High productivity & Low GHG emission & High resilient farming \\
5 & Moderate productivity & Moderate GHG Emission & Moderate resilient farming \\
6 & Low Productivity & Moderate GHG Emission & Low resilient farming \\
7 & Moderate productivity & High GHG Emission & Moderate resilient farming \\
8 & Moderate productivity & High GHG Emission & Low resilient farming \\
9 & High productivity & & \\
\hline
\end{tabular}

All the three CSA attributes/factors were assumed to be discrete in nature. To that effect, the discrete model indicates that the factor levels are categorical and that no assumption is made about the relationship between the factor and the ranks.

Choice Experiment (CE) technique, which has its theoretical background in Lancaster's model of consumer choice $[9,2]$ and its econometric basis from the McFadden's Random Utility Maximization (RUM) theory was applied to model the preferences of smallholder farmers regard to CSA attributes and their levels. CE method applies probabilistic models for choosing between the different alternatives available in each choice set [11].

The basic assumption in choice experiment is that smallholder farmers choose the best bundle of climate smart agricultural practice which maximizes their utility. Accordingly, it is assumed that smallholder farmers can rank their preferences logically and consistently within the limits of their constraints, for example budget and knowledge as explained by [19]. To explore the preference order and trade-offs among multiple attributes of CSA practices, choice modeling using conjoint technique to the attribute levels was carried out. Accordingly, utility maximization gives the behavioural model of decision making $[17,5]$, where;

$$
U_{i}>U_{j} \Rightarrow i \succ j \quad \forall j \in C
$$

This means that the alternative $i$ is chosen over any other alternative $j$ only if it provides highest utility. That is, if the utility of alternative $i$ is greater than the utility of all alternatives, $\mathrm{j}$; Alternative $\mathrm{i}$ will be preferred and chosen from the set of alternatives, $\mathrm{C}$.

$\Rightarrow i \succ j$, means the alternative to the left is preferred to the alternative to the right, and, $\forall j \in C$; means all the cases $\mathrm{j}$, in the choice set $\mathrm{C}$. The probability that alternative $\mathrm{i}$ is chosen is depicted by equation 2 .

$$
\mathrm{P}_{i}=\operatorname{Pr}\left(V_{i}+\varepsilon_{i}>V_{j}+\varepsilon_{j} \forall j \neq i\right)
$$

Furthermore, the Random Utility Maximization (RUM) theory allowed researchers to include some uncertainty in the model as the utility is expressed in observed (deterministic) utility $(V)$ and unobserved (stochastic) utility $(\varepsilon)$. RUT postulates that individual utility (U) is unknown but can be decomposed into a systematic or deterministic component (V) and an unobserved or stochastic component (e). Thus, for individual smallholder farmer $\mathrm{j}$ in scenario $i$, utility was expressed as;

$$
U_{i j}=V_{i j}+\varepsilon_{i j}
$$

The explanatory variables also include the socioeconomic characteristics of a respondent. Since a respondents' 
decision-making process is expected to be iterative and the scenarios will be logically grouped into a decision tree, the nested multinomial logit model is the appropriate model to be used.

Part-worths (conjoint utilities) were expressed in a common unit, allowing them to be added together to give total utility, or overall preference, for any combination of CSA attribute/factor levels. In addition to estimating the impact of each level using the part-worth utilities, the relative importance of each CSA attribute was determined by calculating the range of part-worth utilities (the difference between the highest and lowest utility value). The resulting importance values were converted into percentages by multiplying by 100 as shown in equation 4 .

$$
O_{p}=\frac{\left(\max u_{p}-\min u_{p}\right)}{\sum_{p=1}^{t}\left(\max u_{p}-\min u_{p}\right)} x 100
$$

Where $O_{p}$ is the relative importance of the attribute; $\max u_{p}$ is the utility of the attribute's most preferred level and $\min u_{p}$ is the utility of the least preferred level of the attribute.

\section{Results}

\subsection{Utility Estimates Models}

This study sought to determine the tradeoffs and preferences of smallholder farmers on the proposed climate smart agricultural practices. Three models were estimated as shown in Tables 2, 3, and 4. Positive utilities were observed in the following attribute levels. High productivity, Moderate and low GHG emission as well as on moderate and high resilient farming systems. Smallholder farmers showed a disutility on low and moderate agricultural productivity, high GHG emission and low resilient farming systems. Of all the detested attribute levels, low climate change resilient farming system was the most serious variable, scoring the highest disutility value in all three models.

Table 2. Utilities Estimates (Kilolo Model).

\begin{tabular}{llll}
\hline \multirow{2}{*}{ Attribute } & Attribute Level & $\begin{array}{l}\text { Utility } \\
\text { Estimate }\end{array}$ & $\begin{array}{l}\text { Std. } \\
\text { Error }\end{array}$ \\
\hline \multirow{3}{*}{ APD } & High productivity & 1.143 & 0.365 \\
& Moderate productivity & -0.321 & 0.365 \\
& Low Productivity & -0.821 & 0.365 \\
\multirow{2}{*}{ AGHGE } & High GHG Emission & -0.973 & 0.365 \\
& Moderate GHG Emission & 0.570 & 0.365 \\
& Low GHG emission & 0.403 & 0.365 \\
\multirow{3}{*}{ ACCR } & Low resilient farming & -0.973 & 0.365 \\
& Moderate resilient farming & -0.053 & 0.365 \\
& High resilient farming & 1.027 & 0.365 \\
\hline \multirow{2}{*}{ Constant } & & 5.031 & 0.258 \\
\hline
\end{tabular}

Table 3. Utilities Estimates (Sumbawanga Model).

\begin{tabular}{llll}
\hline Attribute & Attribute Level & $\begin{array}{l}\text { Utility } \\
\text { Estimate }\end{array}$ & $\begin{array}{l}\text { Std. } \\
\text { Error }\end{array}$ \\
\hline \multirow{3}{*}{ APD } & High productivity & 1.040 & 0.208 \\
& Moderate productivity & -0.413 & 0.208 \\
& Low Productivity & -0.627 & 0.208 \\
& High GHG Emission & -0.575 & 0.208 \\
AGHGE & Moderate GHG Emission & 0.425 & 0.208 \\
& Low GHG emission & 0.151 & 0.208 \\
& Low resilient farming & -0.781 & 0.208 \\
ACCR & Moderate resilient farming & 0.168 & 0.208 \\
& High resilient farming & 0.613 & 0.208 \\
\hline \multirow{2}{*}{ Constant } & & 4.832 & 0.147 \\
\hline
\end{tabular}

Table 4. Overall results (Combined Kilolo and Sumbawanga Model).

\begin{tabular}{llll}
\hline Attribute & Attribute Level & $\begin{array}{l}\text { Utility } \\
\text { Estimate }\end{array}$ & $\begin{array}{l}\text { Std. } \\
\text { Error }\end{array}$ \\
\hline \multirow{3}{*}{ APD } & High productivity & 1.095 & 0.277 \\
& Moderate productivity & -0.370 & 0.277 \\
& Low Productivity & -0.725 & 0.277 \\
& High GHG Emission & -0.763 & 0.277 \\
AGHGE & Moderate GHG Emission & 0.458 & 0.277 \\
& Low GHG emission & 0.305 & 0.277 \\
& Low resilient farming & -0.890 & 0.277 \\
& Moderate resilient farming & 0.035 & 0.277 \\
& High resilient farming & 0.855 & 0.277 \\
\hline \multirow{2}{*}{ Constant } & & 4.984 & 0.196 \\
\hline
\end{tabular}

The constant term can be interpreted as base utility, and the other factor values contrast with it in positive or negative direction.

\begin{tabular}{|ll|}
\hline Increase in Productivity & (Low: Moderate: High) \\
Reducing GHG Emissions & (Low: Moderate: High) \\
Increasing Resilience & (Low: Moderate: High) \\
\hline
\end{tabular}

Figure 2. Ideal CSA Model.

\begin{tabular}{|ll|}
\hline Increase in Productivity & (Low: Moderate: High) \\
Reducing GHG Emissions & (Low: Moderate: High) \\
Increasing Resilience & (Low: Moderate: High) \\
\hline
\end{tabular}

Figure 3. Real CSA Model.

\subsection{Relative Importance of CSA Attributes/Factors}

Averaged/Relative importance score tells us that a Combined Conjoint Analysis has been performed. These values give us a measure (in percent) of the relative importance of the single factors for the determination of the utilities. From Table 5, it is shown that, when considering the overall model, productivity is the most important factor whereas Resilience is the least important one. With regard to Sumbawanga and Kilolo models, reduced GHG emissions and Increasing Resilience of the farming systems were found to be the most important CSA factors respectively (see Table 5). 
Table 5. Relative Importance values of CSA Attributes/Factors.

\begin{tabular}{llll}
\hline \multirow{2}{*}{ Model } & CSA Practice Attribute & \\
\cline { 2 - 4 } & $\begin{array}{l}\text { Increased } \\
\text { Agricultural } \\
\text { Productivity }\end{array}$ & $\begin{array}{l}\text { Reduced } \\
\text { Agricultural } \\
\text { Greenhouse Gas } \\
\text { Emissions }\end{array}$ & $\begin{array}{l}\text { Increased } \\
\text { Resilience of } \\
\text { Farming Systems } \\
\text { Climate Change }\end{array}$ \\
\hline $\begin{array}{l}\text { Kilolo Model } \\
\text { Sumbawanga } \\
\text { Model }\end{array}$ & 33.564 & 31.304 & 35.131 \\
$\begin{array}{l}\text { Overall } \\
\text { Model }\end{array}$ & 34.032 & 36.575 & 29.393 \\
\hline
\end{tabular}

\subsection{Model Fitness}

The Pearson's R and Kendall's tau statistics in Table 6 are an indication of how well the models fit the data. They are correlations between the observed and estimated preferences for smallholder farmers to the CSA attributes/factors and their levels. As such, the rule of thumb is that, these coefficients should always be very high, and indeed, they are very high, ranging from 0.966 to 0.980 for Pearson's $\mathrm{R}$, and 0.722 to 0.873 for Kendall's tau coefficient.

Table 6. Model fitness results.

\begin{tabular}{lllllll}
\hline Model fit estimator & Overall Model & $\boldsymbol{p}$-value & Sumbawanga Model & $\boldsymbol{p}$-value & Kilolo Model & $\boldsymbol{p}$-value \\
\hline Pearson's R & 0.974 & 0.000 & 0.980 & 0.000 & 0.966 \\
Kendall's tau & 0.722 & 0.003 & 0.873 & 0.001 & 0.817 \\
\hline
\end{tabular}

The Correlation coefficients are a measure for the quality of reproduction of the empirical data by the results of the conjoint analysis. While Pearson's R measures the relationship between the observed and the predicted preferences of smallholder farmers, Kendall's Tau represents the difference between the probability that the observed data are in the same order versus the probability that the observed data are not in the same order. Overall, the sample of smallholder farmers demonstrates a relatively high convergent validity.

\section{Discussion}

The CSA models developed by this study justify the fact that, attaining more yield without a compromise in greenhouse gas emission reduction targets is a blue-sky dream, and probably next to impossible. This study has therefore proposed the best climate smart agriculture policy model which is also advocated for elsewhere in the world. The concept advocates for high yield, high resilient farming systems, but moderate greenhouse gas emission scenario. Clearing forests, use of fertilizers to boost production, transport of inputs and farm produce are the factors leading to increasing the farm carbon footprint; and these factors therefore validate this model, especially the idea of accommodating moderate greenhouse gas emission instead of low GHG emission scenario, which seems unrealistic (Fig. 2).

The choice experiment results indicate that farmers have their choices and preferences. However, farmers constraints like knowledge and income have to a large extent interfered with informed choice making. Generally, the results give us a glimpse of an idea that, the optimal amount of pollution is not zero. The moment you do not want to see pollution in the environment, is the moment you do not want to see any bit of development and livelihood advancement. However, the optimal level of greenhouse gas emission is that which takes into account all the costs of production, and seeks to promote social welfare and not private benefits. That level of emission has to be decided by the community and not an investor or a scientist for that matter.

While some tradeoffs are inevitable between the three CSA attributes, major synergies exist between climate change mitigation, adaptation to climate change, food security, environmental sustainability and rural social and economic development. These synergies are key to realizing both, mitigation and adaptation in the agricultural sector in Tanzania and worldwide. Smallholder farmers and probably farmers in general are ready to trade-off among the three goals of climate smart agriculture (i.e. increased productivity, reduced agricultural greenhouse gas emissions and increased agricultural resilience, and the findings of this study show that the aspects of climate smart agricultural practices which are the most desirable to smallholder farmers are increased production and resilience.

\section{Conclusion and Recommendations}

These results clearly indicate that a trade-off in the three objectives of climate smart agriculture is inevitable, and thus achieving mitigation in agriculture (more GHG sequestration) without compromising food security is a practical and policy challenge. The overall relative importance of CSA factors and the rating of the importance of CSA factors by Sumbawanga smallholder farmers revealed that inconvenient reality.

Much as low-emission, high climate change resilient and highly productive farming system is ideal, it is not practical, this study has found. In that regard therefore, realizing climate change mitigation in agriculture is both, a policy and research challenge. Climate change-related policies need to be reworked in order to make possible the transition to low-emission agriculture in most developing countries.

In order to concisely inform policy, more research on CSA preference and tradeoff is needed to establish a scientific and logical progression about the tradeoffs people are willing to make with regard to the attributes of climate smart agriculture practices.

\section{Acknowledgement}

This paper was prepared as a contribution to the project titled "Securing Small Holder Farm Production against Climate Induced Risks" which was implemented by Tanzania Environmental Policy Action Node with generous support from the Alliance for a Green Revolution in Africa (AGRA). 
The authors wish to thank Dr. Evelyn Namubiru-Mwaura, the then AGRA Policy Coordinator for her outstanding support to the NODE. Sincere gratitude also goes to the communities and agricultural extension officers in the study areas for providing information and organizing focused group discussions with farmers and key informant interviews. We would also like to thank the following experts for their inputs, effort, and support: Mr. Baran Hintay from the Open University of Tanzania, Mr. Michael Mwaisondola, the Kilolo District Agriculture Officer and Mr. Habona Kwileluyeh, The Sumbawanga District Agriculture, Irrigation and Cooperative Officer.

\section{References}

[1] AGRIFOR Consult ( 2006). Tanzania - Country Environment Study Draft Report. (Unpublished)

[2] Brouwer, R. and Schaafsma, M. (2013) Modelling risk adaptation and mitigation behavior under different climate change scenarios. Climatic Change (2013) 117:11-29 pp.

[3] Claire Schaffnit-Chatterjee (2011). Mitigating climate Change through Agriculture: An untapped Potential. Trend Research. September 19, 2011.

[4] GACP (2011). The economics of climate change in the United Republic of Tanzania. GCAP, January, 2011. Pp 149. Available at http://economics-of-cc-in-tanzania.org. accessed on 5 April 2014.

[5] Hensher D. A. (2004). How do Respondents Handle Stated Choice Experiments? - Information processing strategies under varying information load, DoD Paper \#5, Institute of Transport Studies, The University of Sydney, March.

[6] IFPRI (2007). Climate Change Impacts on Food Security in Sub-Saharan Africa. Insights from Comprehensive Climate Change Scenarios. Ringler C., Zhu, T., Cai, X., Coo, J, and Wang, D. (eds.). Cambridge and New York, Cambridge University Press.

[7] IPCC (2007). Climate Change Impacts, Adaptation and Vulnerability. Contribution of Working Group II to the Fourth Assessment Report of the Intergovernmental Panel on Climate Change. Annex I. M.L. Parry, O.F. Canziani, J.P. Palutikof, P.J. van der Linden and C.E. Hanson (eds.). Cambridge University Press, Cambridge, UK, pp.976.

[8] Kangalawe, R. Y. M. (2012). Food security and health in the southern highlands of Tanzania: A multidisciplinary approach to evaluate the impact of climate change and other stress factors. African Journal of Environmental Science and Technology Vol. 6(1), pp. 50-66.

[9] Lancaster, K. (1966). A new approach to consumer theory. Journal of Political Economy: 74 (1): 132-157.
[10] Lasco, R.D., Habito, C. M. D, Delfifino, R. J. P., Pulhin, F.B. and Concepcion, R.N. (2011). Climate Change Adaptation for Smallholder Farmers in Southeast Asia. World Agroforestry Centre (ICRAF), Laguna, Philippines. pp. 69.

[11] McFadden, D. (1974). Conditional logit analysis of qualitative choice behavior. In: Zarembka, P. (Ed.), Frontiers in Econometrics. Academic Press, New York.

[12] Mongi, H.. Majule, A and J. G. Lyimo (2010). Vulnerability Assessment of Rain Fed Agriculture to Climate Change and Variability in Semi-Arid Tanzania. African Journal of Environmental Science and Technology, Vol. 4: (6): pp. 371-381.

[13] Msangi S, Rosegrant MW, You L (2006). Ex post assessment methods of climate forecast impacts. Clim Res 33:pp.67-97.

[14] Mussa, K. R., Mjemah, I.C and Malisa, E.T. (2012). The role of development projects in strengthening community-based adaptation strategies: The case of Uluguru Mountains Agricultural Development Project (UMADEP)-Morogoro-Tanzania. International Journal of Agricultural Sciences, Vol. 2 (6), pp.157-165.

[15] Mwandosya, M. K. (2007). Report to Plenary Session of the United Nation High Level Meeting on Adaptation to Climate Change. Permanent Mission of the United Republic of Tanzania to the United Nation, Dar es Salaam, 2007.

[16] Rajmis, S, Barkmann, J., and Marggraf, R. (2009). User community preferences for climate change mitigation and adaptation measures around Hainich National Park, Germany. Climate Research. 61-73pp.

[17] Train, K. (2003), Discrete Choice Methods with Simulation, New York: Cambridge University Press.

[18] United Republic of Tanzania (2007). National Adaptation Programme of Action (NAPA). Vice President's Office, Division of Environment. Dar es Salaam, 2007.

[19] Veldhuizena, L.J.L., Tapsuwanb, S. and Burtonc, M. (2011). Adapting to climate change: Are people willing to pay or change? 19th International Congress on Modeling and Simulation, Perth, Australia, 12-16 December 2011. pp.7.

[20] Wongbusarakum, S and Loper, C. (2011). Indicators to assess community-level social vulnerability to climate change: An addendum to SocMon and SEM-Pasifika Regional Socio-economic Monitoring Guidelines. pp. 41.

[21] Yanda, P. Z. Kangalawe, R. Y. M. and Sigalla, R. J. (2006). Climatic and Socio-Economic Influences on Malaria and Cholera Risks in the Lake Victoria Region of Tanzania. ICIFAI Journal of Environmental Economics, Vol. 4, No. 3, 2006, pp. 44-70. 